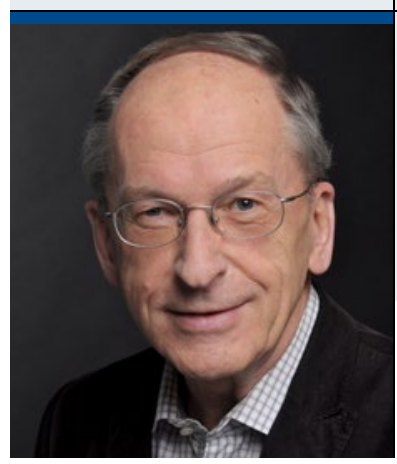

"Zu wenig Impact, geringe Drittmittel, keine Innovation der Urologie fehlt es an geeignetem akademischem

Nachwuchs."

\title{
Ein ungewöhnlicher Werdegang
}

$\mathrm{D}$ er deutsche Urologenkongress wird hoffentlich ein Diskussionsforum, wie es sich viele Mitglieder wünschen. Die URO-NEWS eröffnet diese Diskussion vorab mit nicht alltäglichen Interviews: Klipp und klar beantworten Kollegen die wichtigsten Fragen zum Prostatakarzinom. Lesen Sie mehr dazu auf Seite 29. Einige der behandelten Themen fordern auch Sie als Leser, denn Ihre Meinung ist gefragt!

\section{Freies Spiel der Kräfte}

Unter dem Motto „Hand auf's Herz, was sagen Sie zu Ihrem Standortwechsel?" haben wir den Kollegen Prof. Thomas-Alexander Vögeli zu einem besonderen Interview gebeten (S. 16). Hintergrund ist eine tolle Geschichte: Während normalerweise die akademischen Eliten von der Alma Mater in die Peripherie ziehen, geht jetzt ein langjähriger, verdienter Chefarzt den umgekehrten Weg. Er wechselt von einem 750 Bettenhaus (Träger sind Knappschaft und die Städteregion Aachen) mit einer urologischen 53-BettenAbteilung für seine verbleibende Schaffenszeit von gut sechs Jahren an die Hochschule in Aachen. Dort wird er das Direktorat der Urologischen Universitätsklinik übernehmen. Der Fakultätsrat hat die Wahl inzwischen begrüßt. Was für eine Herausforderung für unseren urologischen Kollegen, Prof. Vögeli!

Was sagt uns der Vorgang? Die Antwort ist vielschichtig. Einerseits könnten die Verhältnisse an seiner alten Arbeitsstätte nicht freudvoll und verträglich gewesen sein - mit anderen Worten, die Interessenlage von Geschäftsführung und ärztlicher Abteilungsleitung waren unterschiedlich. Häufig und in letzter Zeit regelhaft wird dann der ärztliche Kollege verabschiedet. Anders in diesem Fall: Er geht freiwillig und nimmt gleich die gesamte Infrastruktur mit. Da wird es für die Zurückbleibenden - insbesondere für den Geschäftsführer - schwer werden, das Niveau eines akademischen Lehrkrankenhauses aufrechtzuerhalten.

Dass ein Ordinarius den Lehrstuhl wechselt (der Aachener Ordinarius wechselt nach Köln), ist nicht ungewöhnlich und entspricht dem freien Spiel der Kräfte. Diese wirken auch in der Wissenschaft. Der Ordinarius als begehrter Hochschullehrer kann sich durch Berufungsverhandlungen optimieren, und bei günstigen Konstellationen geht er. Die zurückbleibende Fakultät ist gezwungen, Ausschau zu halten. Das hat sie auch in Aachen getan.

Wie aber sieht es mit der akademischen Prominenz unseres Fachgebietes aus? Was sich bereits abzeichnete, wurde hier deutlich: Unter dem akademischen Nachwuchs konnte man nicht fündig werden - zu wenig Impact, geringe Drittmittel, keine Innovation. In nächster Zeit werden bis zu 13, zum Teil hochkarätige Stellen zu besetzen sein. Dieser Nachfrage kann das ohnehin ausgedünnte akademische Angebot nicht entsprechen. Auf einen Bieterwettbewerb wollten sich die Aachener nicht einlassen. Stattdessen schaffen sie eine langfristige Interimslösung - warten also, bis sich die Situation konsolidiert. Aachen hat gesucht und gefunden: einen bewährten Chefarzt, der den Wettbewerb unter den Versorgern kennt, die Leistungsreserven einer Universitätsklink mobilisieren und die für die Versorgungsforschung bereitgestellten Mittel abrufen soll. Für ihn gilt aus urologischer Sicht Schillers Satz „Unter vielen schlimmen Dingen ist das Schlimmste die Zunge“. Mit kritischem Sachverstand wird er das hinterfragen, was vielen eine liebgewordene Gremien-Gewohnheit geworden ist (Schlaf der Arbeitskreise, Selbstbestätigungen auf den jährlichen Mitgliederversammlungen, Ritus und Bewegungslosigkeit der Tagungen Leitender Krankenhausärzte sowie der Hochschullehrer u. v. m.). Kurz gesagt: eine Aufforderung an die Amtsträger, sich einmal mit der Situation zu befassen und bei Bewegungsübungen Ziele zu verfolgen ... sonst könnte der Fall Aachen Schule machen.

Dort hat man jedenfalls eine Entscheidung der Vernunft getroffen!

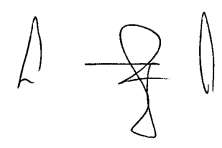

